\title{
Herbal plants that can treat hepatitis in Indonesia
}

\author{
$\underline{\text { Indra SUARDI* }}^{*}$
}

Department of Midwifery, Hasanuddin University, Makassar, South Sulawesi, Indonesia

Introduction: Hepatitis is inflammation of the liver or liver. Hepatitis can be caused by a viral infection, it can also be caused by other conditions or diseases, such as alcohol consumption, use of certain drugs, or autoimmune diseases. If caused by a viral infection, hepatitis can be contagious. Therefore, it is necessary to immediately treat hepatitis patients, one of which is by utilizing herbal plants.

Methods: The method used is studying secondary data from published journals. Of the several collected, 6 articles were selected. The search for articles includes the following criteria; the articles should be published in the last 10 years from 2011 to 2021 and the samples of hepatitis patients are conducted in Indonesia.

Results: Based on the similarity of the dependent variable, found 5 herbal plants that can overcome hepatitis. These herbs are Moringa leaves, Breadfruit Leaves, White Turmeric, Stud Fern Cactus, Eucalyptus. Other studies have shown that health promotion to parents regarding clean and healthy living behaviors can prevent hepatitis.

Conclusions: The people can use herbal plants as an early treatment for hepatitis patients because the use of herbal plants does not require a large fee, is often found in the community, and has minimal side effects. 